\title{
Early detection of infectious complications using C-reactive protein and the procalcitonin levels after laparoscopic colorectal resection: a prospective cohort study
}

\author{
Teppei Tatsuoka ${ }^{1} \cdot$ Takashi Okuyama $^{1}$ (D Emiko Takeshita ${ }^{1} \cdot$ Haruka Oi $^{1} \cdot$ Takuji Noro $^{1} \cdot$ Takashi Mitsui $^{1}$. \\ Hideyuki Yoshitomi ${ }^{1} \cdot$ Masatoshi Oya $^{1}$
}

Received: 30 May 2020 / Accepted: 23 July 2020 / Published online: 12 August 2020

(C) The Author(s) 2020

\begin{abstract}
Purpose The predictive values of the C-reactive protein (CRP) and procalcitonin (PCT) levels for postoperative infectious complications were investigated in patients who underwent elective laparoscopic resection of colorectal cancer.

Methods A total of 154 consecutive patients who underwent elective laparoscopic resection for colorectal cancer (CRC) were prospectively studied. The CRP and PCT levels on the first postoperative day (POD1) and the fourth postoperative day (POD4) were measured. Any correlations between the CRP and PCT levels on POD1 and POD4 with the occurrence of infectious complications were examined.

Results Infectious complications occurred in 18 (11.7\%) patients. CRP on POD1 and CRP and PCT on POD4 were significantly higher in patients who developed infectious complications than in those who did not. The areas under the receiver operating characteristic curves of CRP on POD1 and CRP and PCT on POD4 were 0.597, 0.763 and 0.768, respectively. The cut-off values of CRP and PCT levels on POD4 were $14.33 \mathrm{mg} / \mathrm{dl}$ and 0,264 ng/ml, respectively. Whereas the positive predictive value of an elevated CRP level was high, the negative predictive value of an elevated PCT was high.

Conclusion The CRP and PCT levels on POD4 are both considered to be useful for the early detection of infectious complications after laparoscopic resection of CRC.
\end{abstract}

Keywords Laparoscopic surgery $\cdot$ Colorectal cancer $\cdot$ Postoperative infection $\cdot$ C-reactive protein $\cdot$ Procalcitonin

\section{Introduction}

Infectious complications are relatively common after colorectal resection even in high-volume surgical centers [1,2]. Intra-abdominal infections such as anastomotic leakage and intra-abdominal abscess in particular may cause sepsis and even result in postoperative death.

In recent years, laparoscopic surgery for colorectal resection has become very prevalent. It is usually combined with

Electronic supplementary material The online version of this article (https://doi.org/10.1007/s00595-020-02111-6) contains supplementary material, which is available to authorized users.

Takashi Okuyama

okuyama615@gmail.com

1 Department of Surgery, Saitama Medical Center, Dokkyo Medical University, 2-1-50 Minami-Koshigaya, Koshigaya, Saitama 343-8555, Japan the early recovery after surgery protocol, and some of these patients can develop infectious complications after hospital discharge [3]. In such cases, a delay in the diagnosis and appropriate treatment for infectious complications may result in very serious outcomes.

The usefulness of inflammatory makers including $\mathrm{C}$-reactive protein (CRP) and procalcitonin (PCT) has been described in several reports including a meta-analysis [4, 5]. However, analyses confined to laparoscopic surgery are limited [3]. In the present study, the predictive values of the CRP and PCT levels for postoperative infectious complications after laparoscopic colorectal resection performed at a single surgical department were explored. 


\section{Patients and methods}

The study included 154 consecutive patients (94 men, 50 women) who had undergone elective laparoscopic resection of colorectal cancer in the Department of Surgery at Saitama Medical Center, Dokkyo Medical University, between December 2018 and November 2019. Sixteen patients underwent robot-assisted surgery and the remaining 138 patients underwent conventional laparoscopic surgery. Patients who underwent conversion from laparoscopic to conventional open surgery, and those who underwent synchronous resection of hepatic metastasis were excluded from the present investigation. The median age of the patients was 70.7 years (range, $34-87$ years). The surgical procedures performed for the patients are shown in Table 1.

To measure the serum CRP and PCT levels, peripheral blood was obtained from the cubital vein in the morning on postoperative day (POD1) and POD4. The serum CRP level was measured by latex immunoturbidimetry using a BM6070 (Japan Electron Optics Laboratory, Tokyo, Japan). The serum PCT level was determined by performing an electro-chemiluminescence immunoassay using a Cabas 8000 device (Rosch Diagnostic K.K, Tokyo, Japan) in the routine manner in the clinical laboratory of the hospital. The measurement of the PCT level on POD4 was missing in 18 patients because it was not included in the routine postoperative blood testing protocol. In the present study, white blood cell count (WBC) measured in the routine postoperative laboratory test was also included as a possible co-factor.

Infectious complications were recorded mainly based on clinical symptoms such as fever, pain and tenderness, radiological findings and urinalysis. Intra-abdominal infection was considered present when at least one of the following criteria was met: the presence of pus or enteric contents

Table 1 Performed surgical procedures in the present study

\begin{tabular}{ll}
\hline Performed surgical procedures & \\
\hline Colon & 25 \\
Ileocecal resection & 25 \\
Right hemicolectomy & 4 \\
Transverse colectomy & 9 \\
Left hemicolectomy & 36 \\
Sigmoid colectomy & 12 \\
Anterior resection & 1 \\
Total colectomy & \\
Rectum & 20 \\
Low anterior resection & 11 \\
Very low anterior resection & 9 \\
Abdominoperineal resection & 2 \\
Hartmann operation & \\
\hline
\end{tabular}

within the drains, presence of an abdominal or pelvic collection on postoperative computed tomography (CT), and leakage of contrast media through the anastomosis during an enema or evident anastomotic dehiscence at reoperation for postoperative peritonitis. Wound infection including perineal wound infection after abdominoperineal resection was recorded when the wound was painful or erythematous with pustular discharge and/or a positive culture, the requiring the opening of the wound and the administration of antibiotics. The diagnosis of pneumonia was based on the radiological findings. Urinary tract infection was diagnosed by a positive urine culture and urine sediment findings requiring antibiotic treatment. The diagnosis of enteritis was made when stool cultures were positive for microbial pathogens requiring antibiotic treatment. Peristomal abscess and ischemia of the stoma requiring reoperation were included as infectious complication.

This study was approved by the institutional review board of Saitama Medical Center, Dokkyo Medical University (No. 1582). Before operation, all patients gave their written informed consent to have their postoperative sequential measurement of CRP and PCT levels measured and to undergo an analysis of the associations between their levels and postoperative complications.

\section{Statistical analysis}

Comparisons of the CRP and PCT levels and WBC by the presence or absence of infectious complications were carried out using the Mann-Whitney $U$ test. Receiver operating characteristic curve (ROC) analyses for the correlation of the CRP and PCT levels and WBC with infectious complications were performed, and the respective areas under the curve (AUCs) were calculated to evaluate the predictive values of the CRP and PCT levels and WBC. The optimal cut-off values were obtained from the largest Youden index (Sensitivity + Specificity-1) for each parameter [6]. Multivariate analyses of the CRP and PCT levels and WBC for the prediction of infectious complications were carried out using a multiple logistic regression analysis, with the occurrence of infectious complication as dependent variable, and CRP and PCT levels and WBC on POD1 and POD4 as independent variables. All statistical analyses were performed with the Dr. SPSS software package (SPSS Japan, Tokyo, Japan). $P<0.05$ was considered to indicate a significant difference or correlation.

\section{Results}

Postoperative infectious complications occurred in 18 patients $(11.7 \%)$, of which 16 had surgical site infections (Table 2). Of the 18 patients, intra-abdominal infections such 
Table 2 Postoperative infectious complications in the present study

Postoperative infectious complications

None 136

Surgical site infection

Anastomotic leak

Intra-abdominal abscess

Rectovaginal fistula

Drain site infection

Wound infection

Peristomal infection

Other infectious complications

Urinary tract infection

Enteritis

as anastomotic leak, intraperitoneal abscess and rectovaginal fistula occurred in 12 patients. The infectious complications were diagnosed on POD3 in one patient, on POD 4 in 5 patients, between POD5 and POD7 in 9 patients, and on POD8 or later in 3 patients. In 3 patients who had infectious complications, reoperation was performed. One patient after ileocolic resection who died of intestinal bleeding with intestinal ischemia that occurred on POD9 was not included in the group with infectious complications.

Table 3 compares the CRP and PCT levels and WBC between patients with and without postoperative infectious complications. On POD1, the CRP levels were significantly higher in patients with postoperative infectious complications. On POD4, the CRT and PCT levels and WBC were significantly higher in patients with postoperative infectious complications than in those without (Supplement Table 2).

Figure 1 shows the ROC curves of CRP and PCT levels and WBC on POD1 and POD4. The AUCs of CRP and PCT levels and $\mathrm{WBC}$ on POD1 were $0.645,0.597$ and 0.463 , with $95 \%$ confidence interval (CI) of $0.511-0.781,0.476-0.717$ and $0.311-0.615$, respectively. The AUCs of CRP and PCT levels and WBC on POD4 were $0.763,0.768$ and 0.748 , with a $95 \%$ CI of $0.614-0.913$, and $0.666-0.870$ and $0.625-0.871$, respectively.
From the Youden index, the optimal cut-off value of CRT on POD1 was $9.95 \mathrm{mg} / \mathrm{dl}$. The optimal cut-off values on POD 4 obtained were $14.33 \mathrm{mg} / \mathrm{dl}$ for CRP, $0.264 \mathrm{ng} / \mathrm{ml}$ for PCT and 6.750/ $\mu$ l for WBC. The sensitivity, specificity, positive predictive value (PPV) and negative predictive value (NPV) of CRP level on POD1, and CRP and PCT levels and WBC on POD4 calculated using these cutoff values are shown in Table 4 . The PPV of CRP levels higher than $14.33 \mathrm{mg} / \mathrm{dl}$ on POD4 was $80.0 \%$, whereas the NPV of PCT levels lower than 0.264 was $97.5 \%$.

Table 5 shows the results of multiple logistic regression analyses of the CRP and PCT levels and WBC on POD1 and POD4 for the occurrence of infectious complications. Whereas the CRP level on POD4 was a significant co-factor, the PCT level on POD4 was an independent and nearly significant co-factor. WBC on either POD1 or POD4 was not an independent co-factor (Supplement Table 1).

The relationships between combinations of the CRP and PCT levels on POD4 and postoperative infectious complication are shown in Table 6 . None of the patients with CRP levels $14.33 \mathrm{mg} / \mathrm{dl}$ or higher had PCT levels higher than $0.264 \mathrm{ng} / \mathrm{ml}$. Thus, patients with CRP levels lower than $14.33 \mathrm{mg} / \mathrm{dl}$ and PCT levels higher than $0.264 \mathrm{ng} /$ $\mathrm{ml}$ had an intermediate risk of infectious complications.

Table 7 explores the clinical factors which may influence the CRT and PCT levels on POD4. Elevation of CRP level on POD4 was marginally more frequent in male patients than in female patients. An elevation of the PCT level on POD4 was marginally more frequent in the elderly patients. However, using a multiple logistic regression analysis including age and gender as co-factors, the occurrence of postoperative infection was an independent co-factor associated with elevated CRP and PCT levels on POD4. Tumor site (colon/rectum), body mass index, duration of operation and intraoperative bleeding were not associated with the CRP and PCT levels on POD4.
Table 3 The comparison the CRP and PCT levels and the WBC between the patients with and without postoperative infectious complications

\begin{tabular}{|c|c|c|c|c|c|}
\hline & \multicolumn{2}{|c|}{ Infectious complication $(+)$} & \multicolumn{3}{|c|}{ Infectious complication (-) } \\
\hline & $n$ & Median (interquartile range) & $n$ & Median (interquartile range) & $p$ \\
\hline \multicolumn{6}{|l|}{ POD1 } \\
\hline CRP & 18 & $6.72(4.57-9.66)$ & 136 & $5.15(3.34-7.17)$ & 0.045 \\
\hline PCT & 18 & $0.522(0.321-1.05)$ & 136 & $0.425(0.178-0.873)$ & 0.184 \\
\hline WBC & 18 & $8.1(7-11.1)$ & 136 & $8.6(7.2-10.6)$ & 0.613 \\
\hline \multicolumn{6}{|l|}{ POD4 } \\
\hline CRP & 18 & $13.89(4.25-20.18)$ & 136 & $3.47(2.28-6.92)$ & $<0.001$ \\
\hline PCT & 14 & $0.515(0.274-1.3)$ & 122 & $0.201(0.114-0.418)$ & 0.001 \\
\hline WBC & 18 & $8.1(6.8-9.4)$ & 136 & $6.3(5.2-7.8)$ & 0.010 \\
\hline
\end{tabular}




\section{POD1}

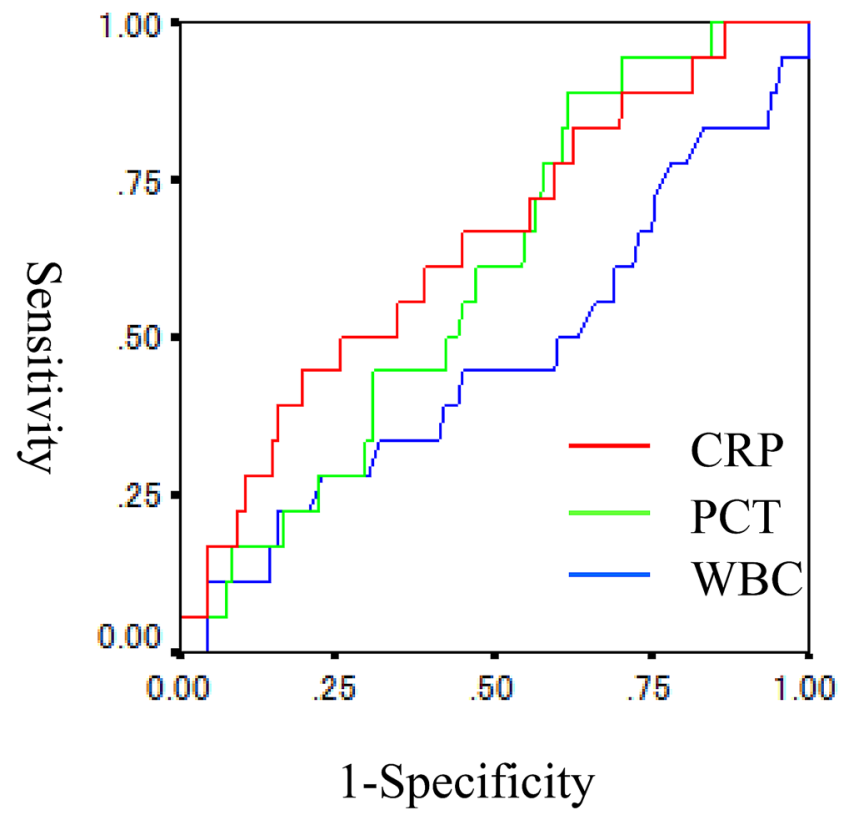

\section{POD4}

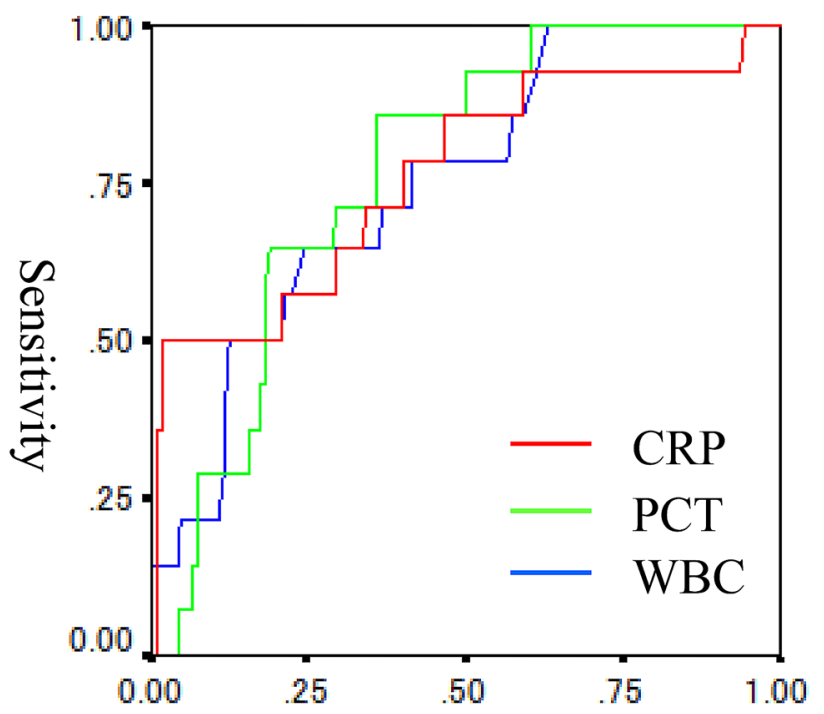

1-Specificity

Fig. 1 The ROC curves of CRP and PCT levels and WBC on POD1 and POD4

Table 4 The sensitivity, specificity, positive predictive value (PPV) and negative predictive value (NPV) of the CRP level on POD1, and the CRP and PCT levels and WBC on POD4 calculated using these cut-off values

\begin{tabular}{|c|c|c|c|c|c|c|c|c|}
\hline \multirow[b]{2}{*}{ Sensitivity } & \multicolumn{2}{|c|}{$\begin{array}{l}\text { CRP on POD1 } \\
\geq 7.95 \mathrm{mg} / \mathrm{dl}\end{array}$} & \multicolumn{2}{|c|}{$\begin{array}{l}\text { WBC on POD4 } \\
\geq 6750 / \mu \mathrm{l}\end{array}$} & \multicolumn{2}{|c|}{$\begin{array}{l}\text { CRP on POD4 } \\
\geq 14.33 \mathrm{mg} / \mathrm{dl}\end{array}$} & \multicolumn{2}{|c|}{$\begin{array}{l}\text { PCT on POD4 } \\
\geq 0.264 \mathrm{ng} / \mathrm{ml}\end{array}$} \\
\hline & $8 / 18$ & $44.4 \%$ & $14 / 18$ & $77.8 \%$ & $8 / 18$ & $44.4 \%$ & $12 / 14$ & $85.7 \%$ \\
\hline Specificity & $110 / 136$ & $80.9 \%$ & $78 / 136$ & $57.4 \%$ & $134 / 136$ & $98.5 \%$ & $78 / 122$ & $59.1 \%$ \\
\hline PPV & $8 / 34$ & $23.5 \%$ & $14 / 72$ & $19.4 \%$ & $8 / 10$ & $80.0 \%$ & $12 / 56$ & $21.4 \%$ \\
\hline NPV & $110 / 120$ & $91.7 \%$ & $78 / 82$ & $95.1 \%$ & $134 / 144$ & $93.1 \%$ & $78 / 80$ & $97.5 \%$ \\
\hline Accuracy & $118 / 154$ & $76.6 \%$ & $92 / 154$ & $59.7 \%$ & $142 / 154$ & $92.2 \%$ & $90 / 136$ & $66.2 \%$ \\
\hline
\end{tabular}

Table 5 The results of multiple logistic regression analyses of the CRP and PCT levels and WBC on POD1 and POD4 for the occurrence of infectious complications

\begin{tabular}{|c|c|c|c|c|}
\hline \multirow[b]{2}{*}{$\begin{array}{l}\mathrm{CRP} \geq 14.33 \mathrm{mg} / \mathrm{dl} \\
\text { vs } \mathrm{CRP}<14.33 \mathrm{mg} / \\
\text { dl }\end{array}$} & \multirow{2}{*}{$\begin{array}{l}\text { Odds ratio } \\
29.40\end{array}$} & \multicolumn{2}{|c|}{$\begin{array}{l}\text { 95\% Confidence } \\
\text { interval }\end{array}$} & \multirow{2}{*}{$\begin{array}{l}p \\
<0.001\end{array}$} \\
\hline & & 4.74 & 182.29 & \\
\hline $\begin{array}{l}\mathrm{PCT} \geq 0.264 \mathrm{ng} / \mathrm{ml} \\
\text { vs } \mathrm{PCT}<0.264 \mathrm{ng} / \\
\mathrm{ml}\end{array}$ & 4.64 & 0.86 & 24.95 & 0.074 \\
\hline
\end{tabular}

\section{Discussion}

Over the last decade, various inflammatory makers have been suggested to assist in the early diagnosis of
Table 6 The relationships between combinations of the CRP and PCT levels on POD4 and postoperative infectious complication

\begin{tabular}{lll}
\hline & \multicolumn{2}{l}{$\begin{array}{l}\text { Infectious complica- } \\
\text { tion }\end{array}$} \\
\cline { 2 - 3 } & Present & Absent \\
\hline $\mathrm{CRP} \geq 14.33 \mathrm{mg} / \mathrm{dl}$ and $\mathrm{PCT} \geq 0.264 \mathrm{ng} / \mathrm{ml}$ & 7 & 2 \\
$\mathrm{CRP} \geq 14.33 \mathrm{mg} / \mathrm{dl}$ and $\mathrm{PCT}<0.264 \mathrm{ng} / \mathrm{ml}$ & 0 & 0 \\
$\mathrm{CRP}<14.33 \mathrm{mg} / \mathrm{dl}$ and $\mathrm{PCT} \geq 0.264 \mathrm{ng} / \mathrm{ml}$ & 5 & 42 \\
$\mathrm{CRP}<14.33 \mathrm{mg} / \mathrm{dl}$ and $\mathrm{PCT}<0.264 \mathrm{ng} / \mathrm{ml}$ & 2 & 78 \\
\hline
\end{tabular}

postoperative infections. Among these, CRP and PCT have been the most commonly used, and, they overall have been identified as good predictors [3, 5, 7-13]. The results of the current study showed that both the CRP and PCT levels on POD4 predicted infectious complications after laparoscopic colorectal resection. According to multivariate 
Table 7 Clinical factors which may influence the CRT and PCT levels on POD4

\begin{tabular}{|c|c|c|c|c|c|c|}
\hline & \multicolumn{3}{|l|}{ CRP on POD4 } & \multicolumn{3}{|l|}{ PCT on POD4 } \\
\hline & $\geq 14.33 \mathrm{mg} / \mathrm{dl}$ & $<14.33 \mathrm{mg} / \mathrm{dl}$ & $p$ & $\geq 0.264 \mathrm{ng} / \mathrm{ml}$ & $<0.264 \mathrm{ng} / \mathrm{ml}$ & $p$ \\
\hline$n$ & 10 & 144 & & 56 & 80 & \\
\hline $\mathrm{Age}^{\mathrm{a}}$ & $70.6(66.5-75.3)$ & $70.7(63.1-76.5)$ & 0.846 & $71.7(67.2-76.4)$ & $70.1(60.2-76.0)$ & 0.067 \\
\hline Gender (male: female) & $9: 1$ & $85: 59$ & 0.052 & $32: 24$ & $48: 32$ & 0.739 \\
\hline $\mathrm{BMI}^{\mathrm{a}}$ & $22.1(21.4-26.4)$ & $23.3(20.3-25.0)$ & 0.739 & $22.8(20.9-25.5)$ & $23.2(20.5-24.8)$ & 0.654 \\
\hline Tumor site (colon: rectum) & $5: 5$ & $107: 37$ & 0.095 & $41: 15$ & $57: 23$ & 0.802 \\
\hline Duration of operation $(\mathrm{min})^{\mathrm{a}}$ & $175.5(147.0-230.3)$ & $181(156.3-261)$ & 0.548 & $175.5(147-23.3)$ & $181(156.3-261)$ & 0.486 \\
\hline Intraoperative bleeding $(\mathrm{g})^{\mathrm{a}}$ & $10(5-475)$ & $12.5(5-30)$ & 0.662 & $10(5-47.5)$ & $12.5(5-30)$ & 0.662 \\
\hline Infection complications (present: absent) & $8: 2$ & $10: 134$ & $<0.001$ & $12: 44$ & $2: 78$ & $<0.001$ \\
\hline
\end{tabular}

${ }^{\mathrm{a}}$ Continuous variables

analyses using a logistic regression analysis, the predictive values of CRP and PCT on POD4 were nearly independent. Although WBC on POD4 was significantly higher in patients with infectious complication than in those without infectious complication, it was not an independent predictor. Using cut-off values of $14.33 \mathrm{mg} / \mathrm{dl}$ for CRP, and $0.264 \mathrm{ng} / \mathrm{ml}$ for PCT on POD4, the PPV of an elevated CRP on POD4 was high $(80 \%)$ whereas the NPV of a low PCT on POD4 was high $(97.5 \%)$. These results suggest that a high CRP on POD4 is useful to identify patients who are likely to develop postoperative infectious complications and that a low PCT on POD4 suggests a postoperative course without infectious complications.

Several previous reports have so far compared the predictive values of CRP and PCT levels for postoperative complications in patients undergoing colorectal surgery with conflicting results. Some studies showed the superiority of the PCT level over the CRP level or the usefulness of the combined analysis of the CRP and PCT levels [8, 9]. In contrast, others reported the superiority of the CRP level over the PCT level or equal predictive values of the CRP and PCT levels $[3,7,10,11]$.

In the present study, the AUCs of the ROC curves of CRP on POD4 and of PCT on POD4 did not differ (0.763 versus 0.768). A meta-analysis by Cousin et al. [4] concluded that the routine measurement of PCT for the prediction of infectious complications had no additional value, because the cost of PCT measurement is much higher than that of CRP. In contrast, a recent systematic review by Tan et al. reported that PCT on POD5 could guide safe discharge after colorectal surgery [5]. Giaccaglia reported that the addition of PCT to CRP provided better ROC curves than PCT or CRP alone [11].

In the current study, the cut-off value of CRP on POD4 calculated using the Youden index was $14.33 \mathrm{mg} / \mathrm{dl}$, slightly higher than the cut-off values in the previous studies [10, 12]. Although the sensitivity of $44.4 \%$ was quite low, the positive predictive value of $80 \%$ was high. The cut-off value of $0.264 \mathrm{ng} / \mathrm{ml}$ for PCT on POD4 was similar to that in a previous study [10] and showed a very high NPV. Actually, the shapes of the ROC curves of CRP and PCT on POD4 were slightly different, though the AUCs were similar. These results suggest that the combination of CRP and PCT level on POD4 is more useful than either the CRP or the PCT level alone.

Since most previous studies included patients who underwent both open surgery and laparoscopic surgery, analyses of patients after laparoscopic surgery have been few [3]. Facy et al. reported that a CRP cut-off value of $10 \mathrm{mg} / \mathrm{dl}$ on POD4 could be applied to both open and laparoscopic colorectal surgeries [12] because they did not find any significant differences in the CRP and PCT levels on POD4 between patients after open surgery and those after laparoscopic surgery if they had intra-abdominal infections. However, laparoscopic surgery is reportedly associated with better short-term clinical and inflammatory outcomes [14, 15]. Laparoscopic surgery has been used for the majority of elective colorectal resection in recent years. Indeed, more than $80 \%$ of elective resections of colorectal cancer were carried out laparoscopically in our department (data not shown). Therefore, exploring the cut-off values only for patients undergoing laparoscopic surgery is thought to be worthwhile (Supplement Table 3). Thus, only patients after laparoscopic surgery were included in the present study.

In the clinical setting, PPV and NPV are often more important than sensitivity and specificity in the decision making. All patients with CRP levels on POD4 over $14.33 \mathrm{mg} / \mathrm{dl}$ had PCT levels on POD4 over $0.264 \mathrm{ng} / \mathrm{ml}$. The PPV of a CRP on POD4 level over $14.33 \mathrm{mg} / \mathrm{dl}$ was $80 \%$, suggesting that patients having such high levels of CRP on POD4 are very likely to develop infectious complication on POD4 or later. In contrast, the NPV of a CRP level $14.33 \mathrm{mg} / \mathrm{dl}$ or higher on POD4 was $93.1 \%$, suggesting that $6.9 \%$ of patients with CRP levels lower than $14.33 \mathrm{mg} / \mathrm{dl}$ on POD4 developed infectious complications. Since postoperative infectious complications occurred in 18 of 154 patients 
(11.7\%), a false negative rate of $6.9 \%$ for CRP on POD4 level might be important. In contrast, only 2 of $80(2.5 \%)$ patients with PCT levels lower than $0.264 \mathrm{ng} / \mathrm{ml}$ on POD4 developed infectious complication. This high NPV appears to be clinically useful because the majority of such patients can be safely discharged especially in the enhanced recovery after laparoscopic surgery protocol.

Patients with CRP levels higher than $14.33 \mathrm{mg} / \mathrm{dl}$ on POD4, even without clinical symptoms, are considered to have an increased risk of infections, and they should be carefully observed until infectious complications are completely ruled out. The removal of intra-abdominal drains should therefore be done very carefully. If they have clinical symptoms such as fever or pain, oral intake should be suspended, and computer tomography (CT) is recommended to detect any areas of abdominal fluid collection, excessive intraabdominal free air, and pneumonia to start early treatment.

In our department, postoperative meal intake was started on POD3 according to the routine postoperative recovery protocol. In the patients of the present study, postoperative oral meal intake was already started at the morning of POD4 in 8 out of 12 patients who developed intra-abdominal infections (anastomotic leak, abscess or rectovaginal fistula). The oral meal intake was stopped on POD4 in 3 patients, and later in 4 patients. The CRP and PCT levels on POD4 were practically utilized in the 3 patients for the determination of suspension of oral intake on POD4 in combination with the clinical symptoms.

The timing of the measurement of the CRP or PCT levels for prediction should be discussed. Although some previous studies measured the CRP or PCT levels daily after operation $[3,7,8,12,16]$, daily measurement is not practical because of its cost. The largest AUC of the ROC curves were obtained for both CRP and PCT levels between POD3 and POD5 in the previous studies [4, 7, 8, 10, 11]. In the present study, CRP and PCT levels were measured on POD1 and POD4, when routine blood tests were scheduled. Since elective colorectal surgery is performed on Monday, Thursday and Friday in our hospital, POD1 and POD4 are usually regular working days. In addition, infectious complications were clinically diagnosed on POD3 in one patient, on POD4 in 5 patients and between POD5 and POD7 in 9 patients, suggesting that the CRP and PCT levels on POD7 are not predictive in the majority of patients with infectious complications.

One limitation associated with the current study is that PCT on POD4 was not measured in 18 patients including 4 patients who developed infectious complications. Although CRP on POD4 was measured as a routine postoperative blood test in 154 consecutive patients, measurement of PCT was not included as a routine blood test on POD4. The missing data for PCT on POD4 in 18 patients might have biased the results. In addition, the results of the present study should be validated using a separate group of patients. For the validation and also for the application as a clinical practice, the measurement of CRP and PCT levels on POD4, and the investigation on the relationship with postoperative infectious complication are continued in patients operated later than December 2019 in our department.

In conclusion, the current study suggests that the measurement of both the CRP and PCT levels on POD4 is useful for predicting postoperative infectious complications after laparoscopic colorectal resection, and that the combination of the CRP and PCT levels on POD4 may enhance the utility of these markers in the postoperative management of patients after laparoscopic colorectal resection.

Author contributions TT, TO and MO designed the study. TT, TO, ET, OH, TN, TM, HY, and MO reviewed the clinical records. TT, TO, and MO analyzed the data. All authors participated in the study design, data interpretation, and critical discussion. TT, TO, and MO wrote the manuscript. All authors read and approved the final manuscript.

Funding This research received no funding support.

Data availability The datasets supporting the conclusion of this article are included within the article. The underlying datasets are available from the corresponding author on reasonable request.

\section{Compliance with ethical standards}

Competing interest Teppei Tatsuoka and the other co-authors have no conflict of interest.

Open Access This article is licensed under a Creative Commons Attribution 4.0 International License, which permits use, sharing, adaptation, distribution and reproduction in any medium or format, as long as you give appropriate credit to the original author(s) and the source, provide a link to the Creative Commons licence, and indicate if changes were made. The images or other third party material in this article are included in the article's Creative Commons licence, unless indicated otherwise in a credit line to the material. If material is not included in the article's Creative Commons licence and your intended use is not permitted by statutory regulation or exceeds the permitted use, you will need to obtain permission directly from the copyright holder. To view a copy of this licence, visit http://creativecommons.org/licenses/by/4.0/.

\section{References}

1. Ikeda A, Konishi T, Ueno M, Fukunaga Y, Nagayama S, Fujimoto $\mathrm{Y}$, et al. Randomized clinical trial of oral and intravenous versus intravenous antibiotic prophylaxis for laparoscopic colorectal resection. Br J Surg. 2016;103:1608-15.

2. Goto S, Hasegawa S, Hata H, Yamaguchi T, Hida K, Nishitai R, et al. Differences in surgical site infection between laparoscopic colon and rectal surgeries: sub-analysis of a multicenter randomized controlled trial (Japan-Multinational Trial Organization PREV 07-01). Int J Colorectal Dis. 2016;31:1775-844. 
3. Munoz JL, Alvarez MO, Cuquerella V, Miranda E, Pico C, Flores $\mathrm{R}$, et al. Procalcitonin and C-reactive protein as early markers of anastomotic leak after laparoscopic colorectal surgery within an enhanced recovery after surgery (ERAS) program. Surg Endosc. 2018;32:4003-100.

4. Cousin F, Ortega-Deballon P, Bourredjem A, Doussot A, Giaccaglia V, Fournel I. Diagnostic Accuracy of Procalcitonin and C-reactive Protein for the Early Diagnosis of Intra-abdominal Infection After Elective Colorectal Surgery: A Meta-analysis. Ann Surg. 2016;264:252-6.

5. Tan WJ, Ng WQ, Sultana R, De Souza NN, Chew MH, Foo FJ, et al. Systematic review and meta-analysis of the use of serum procalcitonin levels to predict intra-abdominal infections after colorectal surgery. Int J Colorectal Dis. 2018;33:171-80.

6. Youden WJ. Index for rating diagnostic tests. Cancer. 1950;3:32-5.

7. Lagoutte N, Facy O, Ravoire A, Chalumeau C, Jonval L, Rat P, et al. C-reactive protein and procalcitonin for the early detection of anastomotic leakage after elective colorectal surgery: pilot study in 100 patients. J Visc Surg. 2012;149:e345-349.

8. Garcia-Granero A, Frasson M, Flor-Lorente B, Blanco F, Puga R, Carratala A, et al. Procalcitonin and C-reactive protein as early predictors of anastomotic leak in colorectal surgery: a prospective observational study. Dis Colon Rectum. 2013;56:475-83.

9. Takakura Y, Hinoi T, Egi H, Shimomura M, Adachi T, Saito Y, et al. Procalcitonin as a predictive marker for surgical site infection in elective colorectal cancer surgery. Langenbecks Arch Surg. 2013;398:833-9.

10. Facy O, Paquette B, Orry D, Binquet C, Masson D, Bouvier A, et al. Diagnostic Accuracy of Inflammatory Markers As Early Predictors of Infection After Elective Colorectal Surgery: Results From the IMACORS Study. Ann Surg. 2016;263:961-6.
11. Giaccaglia V, Salvi PF, Antonelli MS, Nigri G, Pirozzi F, Casagranda B, et al. Procalcitonin Reveals Early Dehiscence in Colorectal Surgery: The PREDICS Study. Ann Surg. 2016;263:967-72.

12. Facy O, Paquette B, Orry D, Santucci N, Rat P, Rat P, et al. Inflammatory markers as early predictors of infection after colorectal surgery: the same cut-off values in laparoscopy and laparotomy? Int J Colorectal Dis. 2017;32:857-63.

13. Goulart A, Ferreira C, Estrada A, Nogueira F, Martins S, Mesquita-Rodrigues A, et al. Early Inflammatory Biomarkers as Predictive Factors for Freedom from Infection after Colorectal Cancer Surgery: A Prospective Cohort Study. Surg Infect (Larchmt). 2018;19:446-50.

14. Ordemann J, Jacobi CA, Schwenk W, Stosslein R, Muller JM. Cellular and humoral inflammatory response after laparoscopic and conventional colorectal resections. Surg Endosc. 2001;15:600-8.

15. Janez J, Korac T, Kodre AR, Jelenc F, Ihan A. Laparoscopically assisted colorectal surgery provides better short-term clinical and inflammatory outcomes compared to open colorectal surgery. Arch Med Sci. 2015;11:1217-26.

16. Dominguez-Comesana E, Estevez-Fernandez SM, Lopez-Gomez V, Ballinas-Miranda J, Dominguez-Fernandez R. Procalcitonin and C-reactive protein as early markers of postoperative intraabdominal infection in patients operated on colorectal cancer. Int J Colorectal Dis. 2017;32:1771-4.

Publisher's Note Springer Nature remains neutral with regard to jurisdictional claims in published maps and institutional affiliations. 